\title{
Role of ecdysone in larval metamorphosis
}

\section{Editorial}

\author{
Sherif M. Abaza
}

Parasitology Department, Faculty of Medicine, Suez Canal University, Ismailia, Egypt

\begin{abstract}
Larvae of almost all insects and nematodes have to undergo a cycle of molting for growing and further development, and with the final molt, adults emerge (complete metamorphosis). In insects, it seems that complete metamorphosis takes place through a dormant stage (pupa), in which all larval cells (muscles, salivary glands, gut, etc.) disintegrate by apoptosis. That is why adult forms appear completely different from their pre-pupa larval stages. In contrast, adult nematodes resemble their final larval stages because dormant pupa stages are absent. In insects, molting with or without pupation requires a pro-thoracicotropic hormone (PTTH) secreted by two pairs of cells in the larval brain. This hormone activates prothoracic glands to secrete a steroid hormone, known as the ecdysone. Also by these glands, sufficient production of the juvenile hormone $(\mathrm{JH})$, promotes larva molting. In case of lower JH production, steroid hormones promote pupation, while complete loss of JH leads to direct formation of the adult from the last final larval molt ${ }^{[1]}$.

Steroid hormones have an essential role on the physiological development and behavior of various organisms. Ecdysone is a major steroid hormone that directs major transitions during developmental stages in the life cycle of some helminth and almost all insects by coordinating larval molting and metamorphosis. Ecdysteroid is produced by the prothoracic gland of all insects as 20-hydroxyecdysone. Increase of ecdysteroid induces the expression of genes controlling protein production for larval development. In adult female insects, ecdysone signaling is critical for reproduction as it mediates egg-chamber maturation during oogenesis, whereas in adult males, ecdysteroids have a role in sperm maturation. It is also present in several plants to protect them from agricultural insects. The ecdysone receptor (EcR) is a nuclear receptor found in the cells of reproduction in all insects, and is activated through binding with ecdysteroid. Once activated, it leads to activation of several genes responsible for physiological changes leading to larval ecdysis (molting). EcR is a non-covalent heterodimer of two proteins; EcR protein and ultraspiracle protein (USP), which are homologous to the mammalian farnesoid X receptor (FXR) and retinoid X receptor (RXR) proteins, respectively. The term USP is usually used for the EcR partner from dipteran and lepidopteran insects, while RXR is applied in other insects. This means that EcR consists of EcR protein and USP for dipteran and lepidopteran insects, whereas it consists of EcR protein and RXR for other insects ${ }^{[2-5]}$.

EcR is mainly applied to control gene expression with two uses; for gene therapy in medical and agricultural fields, and for drug development and vector control in Parasitology researches. The present editorial aims to throw light on the second application.
\end{abstract}

Key Words: 20-hydroxyecdysone, ecdysone, ecdysone receptor (EcR), larva molting, metamorphosis, pro-thoracicotropic hormone, steroid hormone.

Received: 31 March 2017, Accepted: 30 May 2017.

Corresponding Author: Sherif M. Abaza, Tel.: +20-10-0524-3428, E-mail: smabaza@hotmail.com.

ISSN: 1687-7942, Vol. 10, No. 1 \& 2.

Historical background: Ecdysteroids were detected during schistosomula development 10-20 days post infection $^{[6]}$, and as a chemoattractant compound in the extracts of adult female $S$. mansoni ${ }^{[7]}$. As they were excreted in the biological fluids of infected vertebrates, their use as an efficient chemotherapeutic marker was suggested, based on its marked decrease in urine samples after anti-schistosomal treatment ${ }^{[8]}$. Ecdysone and 20-hydroxyecdysone were the major identified compounds of ecdysteroids detected in $H$. diminuta adult worms and eggs $^{[9]}$, and in $O$. volvulus and $O$. gibsoni as well as the bovine tissues harboring them ${ }^{[10]}$. In 1991 was the first study showing that the ecdysteroids have an essential role in larval development of Brugia pahangi and Dirofilaria immitis similar to that found in insects ${ }^{[11]}$. For arthropods, ecdysteroids were detected in incubations of salivary glands, coxal glands, testis, midgut and fat bodies of nymphs belonging to an argasid tick (Ornithodoros parkeri). It was found that ecdysone was secreted by the epidermal cells and converted to 20-hydroxyecdysone using the fat body cells ${ }^{[12]}$. In sequencing of $A$. gambiae prophenoloxidase gene, the investigators detected two ecdysteroid regulatory elements and observed the upregulatory role of 20-hydroxyecdysone on the transcription of this gene in vitro ${ }^{[13]}$.

Drug development: It was in 1993 when the first report was published, dealing with the use of azadirachtin; a non-steroidal ecdysteroid inhibitor. It was found that it abolished molting of $D$. immitis larvae to the fourth stage in vitro ${ }^{[14]}$. Later, the two components of $B$. malayi EcR (BmaEcR and BmaRXR) were identified and the 
investigators proposed the opportunity to use these components for further researches to develop potential drug targets ${ }^{[15]}$. The same American investigators conducted another study to identify presumed ecdysone response elements (EcREs) in B. malayi genome. The results revealed the presence of 18 genes which contained presumed EcREs. They were functionally classified to encode proteins involved in metabolism and developmental transcription. One of these genes was cloned and the investigators induced gene mutation which resulted in loss of ecdysone response, indicating the presence of functional EcREs in the B. malayi genome ${ }^{[16]}$. Recently, the idea of using $B m a E c R$ as new drug target was validated and the American investigators used Ponasterone $\mathrm{A}$ and Muristerone A to treat B. malayi-infected gerbils. Both inhibitors proved to be strong ecdysone agonists ${ }^{[17]}$.

Vector control: The study conducted in Brazil proposed the use of lignoids as an effective insecticide against winged bugs. The investigators used different phytochemicals compounds added to the diet of different species transmitting Chagas' disease, and fed the winged bugs on blood containing T. cruzi epimastigotes. Results revealed that burchellin (a lignoid) significantly decreased their number in the digestive tract ${ }^{[18]}$. The results of another study conducted in Bolivia to evaluate the effect of azadirachtin on the control of Chagas' disease revealed its efficacy to significantly decrease $T$. cruzi epimastigotes in the digestive tract compared to the control larvae (control and ecdysone-treated groups) ${ }^{[19]}$. In 2013, Italian investigators demonstrated a close cooperation between 20-hydroxyecdysone and EcR of A. gambiae mosquitoes. It was found that eggs development was regulated through interaction between male 20-hydroxyecdysone and a female protein called mating-induced stimulator of oogenesis. The latter was highly expressed after mating and the interaction was produced via the female EcR. Therefore, the investigators recommended to benefit from this interaction as a new method for control of malaria transmission $^{[20]}$.

\section{REFERENCES}

1. http://www.biology-pages.info/I/insecthormones. html:Insect hormones In: Kimball's Biology. Updated 8 December, 2016.

2. Henrich VC. The ecdysteroid receptor. In Gill SS, Gilbert LI, Iatrou K (Editors). Comprehensive molecular insect science. Elsevier; Amsterdam: 2005, pp. 243-285.

3. Palli SR, Hormann RE, Schlattner U, Lezzi M. Ecdysteroid receptors and their applications in agriculture and medicine. Vitam Horm 2005; 73: 59-100.
4. Graham LD. Ecdysone-controlled expression of transgenes. Expert Opin Biol Ther 2002; 2(5): 525-535.

5. Ishimoto $\mathrm{H}$, Kitamoto $\mathrm{T}$. The steroid molting hormone ecdysone regulates sleep in adult Drosophila melanogaster. Genetics 2010; 185(1): 269-281.

6. Torpier G, Hirn M, Nirde P, De Reggi M, Capron A. Detection of ecdysteroids in the human trematode, Schistosoma mansoni. Parasitology 1982; 84(1): 123-130.

7. Childs JE, Shirazian D, Gloer JB, Schiller EL. In vitro orientation of male Schistosoma mansoni to extracts derived from female schistosomes. J Chem Ecol 1986; 12(8): 1729-1738.

8. Nirdé P, De Reggi ML, Capron A. Fundamental aspects and potential roles of ecdysteroids in schistosomes an update overview. J Chem Ecol 1986; 12(8): $1863-1884$

9. Mercer JG, Munn AE, Arme C, Rees HH. Analysis of ecdysteroids in different developmental stages of Hymenolepis diminuta. Mol Biochem Parasitol 1987; 25(1): 61-71.

10. Mercer JG, Barker GC, Howells RE, Rees HH. Analysis of ecdysteroids in Onchocerca gibsoni, O. volvulus and nodule tissues. Trop Med Parasitol 1989; 40(4): 434-439.

11. Barker GC, Mercer JG, Rees HH, Howells RE. The effect of ecdysteroids on the microfilarial production of Brugia pahangi and the control of meiotic reinitiation in the oocytes of Dirofilaria immitis. Parasitol Res 1991; 77(1): 65-71.

12. Zhu XX, Oliver JH Jr, Dotson EM. Epidermis as the source of ecdysone in an argasid tick. Proc Natl Acad Sci USA 1991; 88(9): 3744-3747.

13. Ahmed A, Martín D, Manetti AG, Han SJ, Lee WJ, Mathiopoulos KD et al. Genomic structure and ecdysone regulation of the prophenoloxidase 1 gene in the malaria vector Anopheles gambiae. Proc Natl Acad Sci USA 1999; 96(26): 14795-14800.

14. Warbrick EV, Barker GC, Rees HH, Howells RE. The effect of invertebrate hormones and potential hormone inhibitors on the third larval moult of the filarial nematode, Dirofilaria immitis, in vitro. Parasitology 1993; 107(4): 459-463.

15. Tzertzinis G, Egaña AL, Palli SR, Robinson-Rechavi M, Gissendanner CR, Liu C et al. Molecular evidence for a functional ecdysone signaling system in Brugia malayi. PLoS Negl Trop Dis 2010; 4(3): e625. 
16. Liu C, Enright T, Tzertzinis G, Unnasch TR. Identification of genes containing ecdysone response elements in the genome of Brugia malayi. Mol Biochem Parasitol 2012; 186(1): 38-43.

17. Mhashilkar AS, Vankayala SL, Liu C, Kearns F, Mehrotra P, Tzertzinis G et al. Identification of ecdysone hormone receptor agonists as a therapeutic approach for treating filarial infections. PLoS Negl Trop Dis 2016; 10(6): e0004772.

18. Garcia ES, Azambuja P. Lignoids in insects: chemical probes for the study of ecdysis, excretion and
Trypanosoma cruzi-triatomine interactions. Toxicon 2004; 44(4): 431-440.

19. Cortez MR, Provençano A, Silva CE, Mello CB, Zimmermann LT, Schaub GA et al. Trypanosoma cruzi: effects of azadirachtin and ecdysone on the dynamic development in Rhodnius prolixus larvae. Exp Parasitol 2012; 131(3): 363-371.

20. Baldini F, Gabrieli P, South A, Valim C, Mancini F, Catteruccia $\mathrm{F}$. The interaction between a sexually transferred steroid hormone and a female protein regulates oogenesis in the malaria mosquito Anopheles gambiae. PLoS Biol 2013; 11(10): e1001695. 